\section{Spider Myths and a Case of a Bite by a Yellow Sac Spider}

To the Editor: We enjoyed reading Frithsen's ${ }^{1}$ report on the paradox of the number of reported spider bites exceeding the number of Loxosceles spiders in South Carolina. As an amendment, we would like to draw attention to spider myths in Central Europe. A 31-year-old male patient was admitted to our hospital after a bite from a spider that had found shelter in his slipper. His toe showed local edema and erythema, and he reported severe pain comparable to a hornet sting. No generalized symptoms occurred. The patient caught the mediumsized, long-legged, golden and straw-colored spider with pedipalps and multiple dorsal eyes, and brought the living spider with him in a glass. The spider was identified as a yellow sac spider (genus Cheiracanthium, Figure 1). According to review articles, medical textbooks, and medical journal correspondences, yellow sac spiders are considered to be the only potentially dangerous spiders in Central Europe causing dermonecrosis. ${ }^{2,3}$ This is not supported by a case series of 20 verified bites by Cheiracanthium spiders from the United States and Australia (none with necrosis), nor by a review of the international literature on 39 verified Cheiracantbium bites (which found only one case of mild necrosis in the European species, Cheiracanthium punctorium, nearly 50 years ago)..$^{3,4}$ No verified case of a Cheiracanthium bite in Central Europe has been reported since then in medical literature, but reports of spider sightings have dominated local media in Austria for a year, triggering hundreds of calls to the Vienna poison hotline and prompting the government to issue a plea for calm. ${ }^{5}$ Spider mythology and spider phobia are clearly phenomena not only of the past. ${ }^{5}$ Our patient recovered completely within a few days after symptomatic therapy.

Michael Fasan, MD Alexandra Rennhofer, MD

Bernadetta Moser, MD

Georg Röggla, MD

Department of Internal Medicine, General Hospital of Neunkirchen, Neunkirchen, Austria roeggla.interne@khneunkirchen.at

\section{References}

1. Frithsen IL, Vetter RS, Stocks IC. Reports of envenomation by brown recluse spiders exceed verified specimens of Loxosceles spiders in South Carolina. J Am Board Fam Med 2007;20:483-88.

2. Durrheim D, Barnett FI. Necrotic arachnidism: dispelling fact with fiction. Lancet 2004;364:2018-9.

3. Vetter RS, Isbister GK, Bush SP, Boutin LJ. Verified bites by yellow sac spiders (genus Cheiracanthium) in the United States and Australia: where is the necrosis? Am J Trop Med Hyg 2006;74:1043-8.
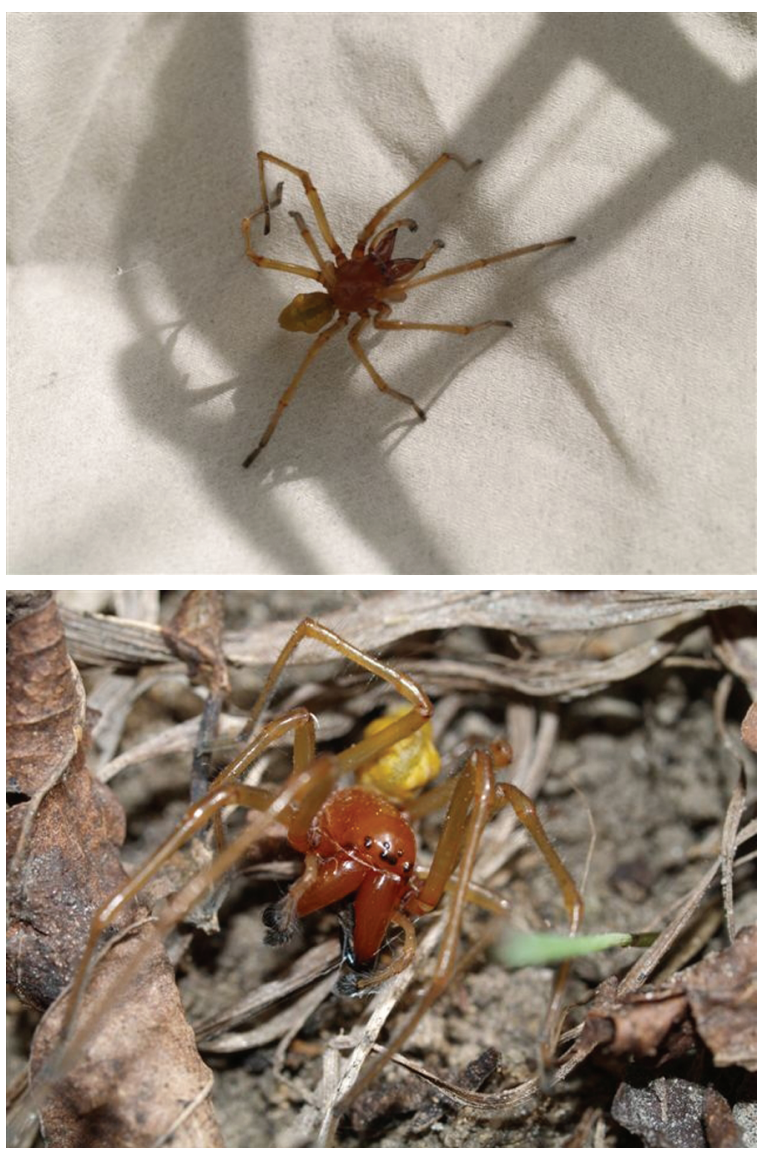

Figure 1. Yellow sac spider (genus Cheiracanthium)

4. Maretic Z. Chiracanthium punctorium Villers - eine europäische Giftspinne. Med Klin 1962;37:1576-7.

5. Isbister GK. Necrotic arachnidism: the mythology of a modern plague. Lancet 2004;364:549-53.

doi: 10.3122/jabfm.2008.01.070218

Note: Frithsen declined to respond because the author is in agreement.

\section{Community-based Participatory Research: Providers, Patient, and Community in Partnership to Improve Health Disparities}

To the Editor: Rust and Cooper ${ }^{1}$ present a case for improving health disparities through practice-based research and 12 strategies to close the gap on health outcomes disparities. Community-based participatory research (CBPR) complements cooperative grants in select regions and forms a fundamental basis for these strategies. CBPR promotes the conduct of research in "real 